\section{Setting logical priorities}

\section{A boycott is not the best route to free exchange of scientific information.}

\section{Ira Mellman}

I am neither a publisher nor a professional editor. I am a practising scientist who, with 60 colleagues, collaborates with the nonprofit Rockefeller University Press to produce a high-quality publication, The Journal of Cell Biology (JCB; http://www.jcb.org). We do not aim to make a profit and have no vested interest in publishing. We do feel that, by helping to maintain a pre-eminent public forum for cell biologists worldwide, we are making an important contribution to our field, and to science in general.

I have long been an enthusiastic supporter of removing the barriers to free exchange of scientific information. The Public Library of Science (PLS; http://www.publiclibraryofscience.org) boycott initiative has the potential to provoke some important changes in this regard. As I and so many of my colleagues support the idea that journals should release their content six months following publication, the JCB has enthusiastically adopted this policy.

One would think that the biggest priority should now be to persuade other organizations, including the Nature Publishing Group (NPG; publisher of the Nature journals) and Elsevier Science (publisher of Cell and many other journals), to follow suit. Such commercial publishers have so far seemed ill-inclined to make their content free at any time after publication. This should be cause for considerable concern as together NPG and Elsevier produce some of our most widely read journals.

The PLS group has chosen a different and diversionary path. Not content to focus on ensuring public release of journal content, it has also demanded that released content be available for posting on any web server, anywhere. This demand appears to be poorly thought out, unnecessary, a waste of money and a potentially dangerous threat to scientific exchange forums such as the JCB. Moreover, to make such a demand by threatening a boycott of even those journals run by scientists for scientists strikes me as being needlessly anticollegial and counterproductive. This is not how science typically makes progress.

Why is the PLS demand for multipleserver release a bad idea? The nature of scientific information makes its reproduction delicate. It is not just plain text and sequences. Complications arise, for example in producing the myriad special symbols involved and in displaying complex visual images integral to many papers, particularly in cell biology. Each journal has its own translation software to take material formatted for publication of a print version and convert that material into a digital, online version. Frequent manual interventions are needed to correct the inevitable errors. Posting this information on each new site is fraught with the same difficulties. There is no software package or standard to ensure the accuracy of each reposting, and the PLS has not thought through who will assume all the added costs.

Maintaining the integrity of the publication process is vital, in print or online. It is the responsibility of a journal to ensure that the science it publishes is a faithful, accurate and accessible version of the manuscripts it accepts for publication. It is not a process that should be ceded to unknown individuals or, in the case of PubMed Central (http://www.pubmedcentral.nih.gov), an agency of the US government.

\section{Copyright conundrum}

Viewed in this way, the issue of who owns copyrights is an ideological red herring, at least in the case of nonprofit publishers. As individual authors, we cannot protect our work from being re-posted on a multitude of servers, each with its own set of errors and deficiencies such as the loss of corrections, supplementary material and hyperlinks. Nor could we effectively monitor the repackaging of our work for resale by others. The Rockefeller University Press retains copyright of material published in the JCB not to make a profit, but to protect the integrity of the papers it publishes. Crucially, authors of JCB papers are free to reproduce their work for any scholarly or educational activity.

Many technical problems could be solved by investing money in software development. But is this necessary or advisable? Given that a revolution in scientific publishing was well under way even before PLS, what is the justification for the expenditure of public funds to duplicate efforts (such as the nonprofit HighWire Press) that are already successful? The

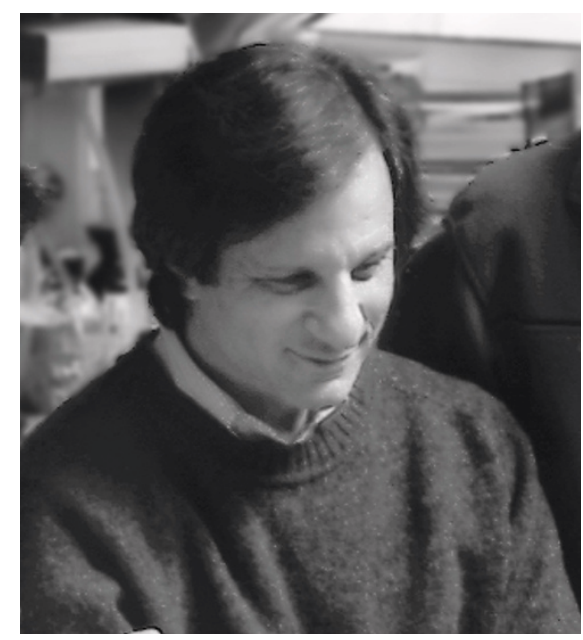

Extra effort: Ira Mellman says the burden of peer-review should not be underestimated. end result would be a database lacking material from the preceding six months - of interest to few scientists. It would be far more logical to invest in increasing the power of websites such as PubMed (http://www.ncbi.nlm.nih.gov/PubMed) that permit searches on other sites without that material needing to be re-displayed. It is outmoded and incorrect to contend, as does the PLS, that hosting content on single sites is necessary for complete searching.

It is unfortunate that the PLS boycott lumps together all types of journals: commercial and nonprofit, high-quality/high-circulation and archival or marginal-quality/ low-circulation. It is perhaps a worthy goal to eliminate the last of these groups, many of which are probably poorly peer-reviewed, not widely read, and exist primarily to increase the profit margins of large-scale publishers. Their disappearance would save millions of dollars for libraries that are forced into subscribing to entire portfolios of such titles.

Ironically, the PLS demand for server release may pose the greatest risk to journals without large corporate sponsors, without government sponsors (as enjoyed by the Proceedings of the National Academy of Sciences) or without professional societies willing to bear chronic losses (for example, Molecular Biology of the Cell). If such journals, for example the JCB or the EMBO Journal, are forced to abandon their websites, their revenue and identities will be compromised, leading to the disappearance of the highquality, well-read journals on which we rely for the best papers in our fields.

Even nonprofit, noncommercial journals need money to survive. After printing costs, the main expense faced by journals such as the $J C B$ is the maintenance of an efficient reviewing system. When hard-copy journals finally disappear, our collective costs will drop; but high-quality and timely reviewing will still require a source of continuing revenue. Although imperfect, peer review has served the cause of science well. It can only increase in importance as the volume of scientific information increases. Guiding a scholarly and fair peer-review process is a challenge whose importance and complexity is underestimated by PLS as well as several other commercial online initiatives.

If readers were ultimately steered away from journal sites, journals would have insufficient funds to continue. If this risk were necessary to ensure the free exchange of scientific information, I would be advocating that we take it. The PLS initiative does not, however, make a persuasive case that the risk is necessary to achieve the desired result. Therefore, taking such a risk is not a logical approach to the problem.

Ira Mellman is chairman of the Department of Cell Biology, Ludwig Institute for Cancer Research, Yale University School of Medicine, PO Box 208002, New Haven, Connecticut 06520, USA. 